\title{
Health-related quality of life of patients with inflammatory bowel disease in Singapore
}

\author{
Prisca Yue Min $\mathrm{Ho}^{1}$, Wenjia Hu${ }^{1}$, Ying Yun Lee ${ }^{2}$, Chuxi Gao ${ }^{3}$, Yan Zhi Tan ${ }^{3}$, Hua Heng Cheen ${ }^{3}$, Hwee Lin Wee \\ Teong Guan Lim³, Wan Chee Ong ${ }^{3}$ \\ ${ }^{I}$ Department of Pharmacy, Faculty of Science, National University of Singapore, Singapore; ${ }^{2}$ Department of Pharmacy, Woodlands Health \\ Campus, Singapore; ${ }^{3}$ Department of Pharmacy, Singapore General Hospital, Singapore
}

Background/Aims: Inflammatory bowel disease (IBD) is associated with considerable impairment of patients' health-related quality of life (HRQoL). Knowledge of factors that significantly affect IBD patients' HRQoL can contribute to better patient care. However, the HRQoL of IBD patients in non-Western countries are limited. Hence, we assessed the HRQoL of Singaporean IBD patients and identified its determinants. Methods: A prospective, cross-sectional study was conducted at Singapore General Hospital outpatient IBD Centre. The HRQoL of IBD patients was assessed using the short IBD questionnaire (SIBDQ), Short Form-36 physical and mental component summary (SF-36 PCS/MCS) and EuroQol 5-dimensions 3-levels (EQ-5D-3L) and visual analogue scale (VAS). Independent samples t-test was used to compare HRQoL between Crohn's disease (CD) and ulcerative colitis (UC). Determinants of HRQoL were identified through multiple linear regression. Results: A total of 195 IBD patients (103 UC, $92 \mathrm{CD}$ ) with a mean disease duration of 11.2 years were included. There was no significant difference in HRQoL between patients with UC and CD. Factors that significantly worsened HRQoL were presence of active disease (b=-6.293 [SIBDQ], -9.409 [PCS], -9.743 [MCS], -7.254 [VAS]), corticosteroids use (b=-7.392 [SIBDQ], -10.390 [PCS], -8.827 [MCS]), poor medication adherence $(\mathrm{b}=-4.049$ [SIBDQ], -1.320 [MCS], -8.961 [VAS]), presence of extraintestinal manifestations $(\mathrm{b}=-13.381$ [PCS]), comorbidities ( $b=-4.531$ [PCS]), non-employment ( $b=-9.738$ [MCS], -0.104 [EQ-5D-3L]) and public housing ( $b=-8.070$ [PCS], -9.207 [VAS]). Conclusions: The HRQoL is impaired in this Asian cohort of IBD. The magnitude of HRQoL impairment was similar in UC and CD. Clinical characteristics were better determinants of patients' HRQoL than socio-demographic factors. Recognizing the factors that impact patients' HRQoL would improve the holistic management of IBD patients. (Intest Res 2019;17:107-118)

Key Words: Inflammatory bowel disease; Ulcerative colitis; Crohn's disease; Singapore; Health-related quality of life

\section{INTRODUCTION}

Inflammatory bowel diseases (IBD), consisting of CD and UC, are chronic inflammatory disorders of the GI tract. Complex interactions between environmental, genetic and immuno-

Received July 9, 2018. Revised October 1, 2018

Accepted October 4, 2018.

Correspondence to Wan Chee Ong, Department of Pharmacy, Singapore

General Hospital, Outram Road, 169608, Singapore. Tel: +65-9111-8397,

Fax: +65-6323-1335, E-mail: ong.wan.chee@sgh.com.sg

ORCID Prisca Yue Min Ho (https://orcid.org/0000-0002-0673-5687), Wan

Chee Ong (https://orcid.org/0000-0001-6733-9162) logical factors are thought to underlie the disease development, leading to a dysregulated immune response to intestinal microbiota. ${ }^{1}$ Over the past few decades, IBD has become more prevalent in Asia. ${ }^{2}$ In Singapore, close to 2,000 patients suffer from IBD. ${ }^{3}$

Chronic nature of the disease, frequent recurrence of debilitating GI symptoms, extraintestinal manifestations (EIMs), the effects of medical treatments and the associated side effects, worries about developing cancer and the need for surgical interventions as well as hospitalizations place substantial burden on the daily lives of IBD patients and cause significant im- 
pairment in their health-related quality of life (HRQoL) ${ }^{4.7}$

HRQoL is defined as a multi-dimensional concept that incorporates the physical, social and emotional features of health perception and health functioning. ${ }^{8.9}$ Assessment of HRQoL is increasingly becoming an important aspect of medical decision-making, as improving HRQoL is a major goal of therapy and value-based healthcare. ${ }^{10}$ In IBD, poorer HRQoL have been reported compared to the general population. ${ }^{11,12}$ Therefore, evaluating and improving their HRQoL are as important as controlling the disease activity.

Numerous clinical and demographic factors have consistently been identified to be associated with poorer HRQoL. These factors include disease activity, symptom severity, number of relapses, surgical procedures and work absenteeism. ${ }^{7,1,14}$ However, conflicting data exists across studies from different countries or population types for other factors such as disease duration, IBD treatments, age, gender, educational and smoking status. ${ }^{13-17}$

As majority of the HRQoL studies were conducted in Western countries, their findings may not be representative of the IBD population in Singapore due to cultural differences and different coping strategies. ${ }^{18,19}$ This is evident in 2 China studies which have acknowledged that the differences in clinical characteristics of IBD in the Chinese population, as well as cross-cultural and behavioral differences, could have led to deviations in their findings when compared to that of the Western population. ${ }^{13,20}$ Furthermore, the HRQoL of IBD patients in Singapore has not been sufficiently investigated.

Therefore, the aim of this study is to assess and compare the HRQoL of IBD patients in Singapore, and to identify the sociodemographic and clinical factors influencing their HRQoL. Knowledge of the HRQoL of IBD patients and its associated factors will provide a better understanding of patients' global situation and aid in provision of more personalized care.

\section{METHODS}

\section{Study Design and Ethical Considerations}

We conducted a prospective, cross-sectional study involving patients with IBD recruited from the outpatient IBD Centre at Singapore General Hospital between August 2016 and September 2017. Patients aged $\geq 21$ years with an established IBD diagnosis, on IBD medication therapy and ability to read and comprehend English, and ability to provide informed consent were included. Non-Singaporeans and patients with neuropsychiatric conditions which may impair their ability to re- spond to the HRQoL evaluation were excluded. The study was approved by the SingHealth Centralized Institutional Review Board (CIRB No. 2016/2636). Informed consent was obtained from each patient in the study. The study protocol conforms to the ethical guidelines of the 1975 Declaration of Helsinki (6th revision, 2008) as reflected in a priori approval by the institution's human research committee.

\section{Study Procedure}

Patients with IBD were approached as they awaited consultation with a gastroenterologist. A set of self-administered or interviewer-administered questionnaires on HRQoL and disease activity were given to patients following consent taking. Patients' demographic information, details on medication use and adherence, clinical diagnosis and disease characteristics were obtained from both the questionnaires and electronic medical records.

\section{Demographics and Disease Characteristics}

Demographic variables obtained were age, gender, race, education, employment, monthly income, housing, marital status and smoking status. Patients' disease characteristics obtained were their diagnosis (UC or CD), disease duration, disease location and behavior, presence of perianal disease or EIMs, laboratory results (CRP and fecal calprotectin $[\mathrm{FC}]$ concentrations), number of hospitalizations and surgical procedures over the past 1 year, and Charlson Comorbidity Index (CCI). ${ }^{21}$

The types of common treatment modalities identified were 5-aminosalicylic acid (5-ASA), immunomodulators, corticosteroids and biologics. Patients' adherence was assessed using the Medication Adherence Report Scale (MARS-5). The MARS5 consists of 5 common patterns of medication non-adherence behavior. Scores on a 5-point Likert scale were summed, ranging from 5 to 25 . A score of $\geq 20$ was considered adherent. $^{22}$

\section{Measurements of HRQoL}

Patients' HRQoL was measured using the short IBD questionnaire (SIBDQ), Short Form-36 Health Survey (SF-36) and EuroQol 5-dimensions 3-levels (EQ-5D-3L). The minimum clinically important difference (MCID) of the respective instruments was used to assess the clinical significance, given a statistically significant result. MCID represents the smallest difference in scores that is considered to be clinically significant and is selected based on literature review. 


\section{1) Short IBD Questionnaire}

The SIBDQ is a 10-item disease-specific questionnaire, which measures 4 domains of HRQoL, comprising social performance, emotional status, bowel function and systemic symptoms. ${ }^{23}$ Scores from individual domains are summed to obtain a total score ranging from 10 to 70 , which correspond to poor-to-good HRQoL respectively. The selected MCID of the SIBDQ is 10 points. ${ }^{23}$ The SIBDQ has been validated in IBD populations. ${ }^{24}$

\section{2) Short Form-36 Health Survey}

The SF-36 survey is the most widely used generic profile-based HRQoL instrument in research. ${ }^{11,25}$ It consists of 36-item questions that are categorized into 8 domains (physical functioning, role limitations due to physical health problems, bodily pain, social functioning, role limitations due to emotional problems, general mental health, vitality or energy level, and general health perceptions). ${ }^{25}$ It can generate 2 summary scores: physical component summary (PCS) and mental component summary (MCS). Higher scores indicate better physical and mental health respectively. The MCID of SF-36 is 5 points. ${ }^{26}$ Population norms are available for Singapore's general population. $^{27,28}$

\section{3) EuroQol 5-Dimensions}

The EQ-5D is a generic preference-based questionnaire validated for the assessment of HRQoL in the IBD patient populations and Singapore population. ${ }^{29-31}$ It covers 5 dimensions: mobility, self-care, usual activity, pain and discomfort and anxiety/depression. Patients are required to rate each dimension on 3 levels, reflecting no problem, some problem, and extreme problem. ${ }^{32}$ The dimensional scores are subsequently used to derive a utility score. The questionnaire also includes a $20 \mathrm{~cm}$ visual analogue scale (VAS) that allows patients to rate their state of health by drawing a line from an anchor box to the point on the VAS which best represents their health on that present day. The MCID of EQ-5D utility score and VAS are 0.08 and 10 points respectively. ${ }^{26,29}$

\section{Measurements of Disease Activity}

The CRP levels in blood samples were used as an objective marker of inflammation, and values $>9.1 \mathrm{mg} / \mathrm{L}$ were considered elevated. FC concentrations were also used to determine disease activity, and an elevated FC level was defined as $>200 \mu \mathrm{g} / \mathrm{g}$.

Disease activity were assessed using the Partial Mayo index (PMI) for UC and Harvey-Bradshaw Index (HBI) for CD. ${ }^{33,34}$ These 2 indices are chosen because they are widely used in clinical trials, non-invasive and rely entirely on symptoms of the patient. A PMI score of $\leq 1$ indicates remission, 2-4 indicates mild disease, 5-6 indicates moderate disease and 7-9 indicates severe disease whereas an HBI score of $<5$ indicates remission, 5-7 indicates mild disease, 8-16 indicates moderate disease and score $>16$ indicates severe disease. ${ }^{33,34}$ The disease activity was further dichotomized into remission or active disease in the data analysis.

\section{Statistical Analysis}

Statistical analyses were performed using IBM SPSS version 24 (IBM Corp., Armonk, NY, USA). Descriptive statistics were used to summarize patient demographics and clinical characteristics. Continuous variables were presented as mean and SD, while categorical variables were presented as frequency and percentage.

The HRQoL data were presented as dimensional and total scores for SIBDQ, dimensional and component summary scores for SF-36, utility scores for EQ-5D and total scores for EQ-VAS. Chi-square test, independent samples $t$-test and MannWhitney test were conducted for categorical, normal and skewed continuous variables respectively. As UC and CD patients had similar HRQoL scores, patient data from both groups were pooled together for subsequent analyses.

Multiple linear regression was used to identify variables that

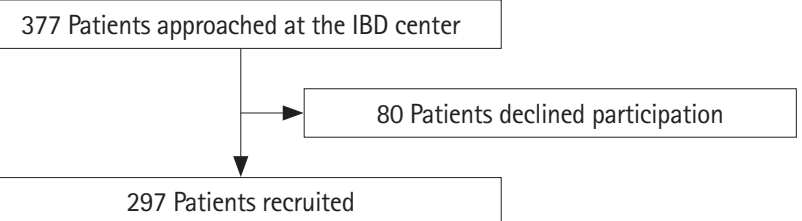

80 Patients did not meet inclusion criteria 38 Unable to read or comprehend English 26 Underage ( $<21$ years old) 11 Without a confirmed UC or CD diagnosis 5 Not taking medication for IBD 15 Patients excluded 9 Foreigners 4 Diagnosed with psychiatric disorders 2 Diagnosed with Behçet disease

202 Patients included in study

7 Patients with incomplete data

195 Patients included in final analysis (103 UC, 92 CD)

Fig. 1. Study flowchart. 
Table 1. Demographics and Clinical Characteristics of Participants

\begin{tabular}{|c|c|c|c|c|}
\hline Characteristics & All patients $(n=195)$ & UC $(n=103)$ & $C D(n=92)$ & $P$-value \\
\hline \multicolumn{5}{|l|}{ Socio-demographics } \\
\hline Age (yr) & $47.1 \pm 15.3$ & $51.4 \pm 13.6$ & $42.3 \pm 15.8$ & $<0.001$ \\
\hline Sex & & & & 0.200 \\
\hline Male & $131(67.2)$ & $65(63.1)$ & $66(71.7)$ & \\
\hline Female & $64(32.8)$ & $38(36.9)$ & $26(28.3)$ & \\
\hline Race & & & & 0.992 \\
\hline Chinese & $123(63.1)$ & $65(63.1)$ & $58(63.0)$ & \\
\hline Malay & $16(8.2)$ & $8(7.8)$ & $8(8.7)$ & \\
\hline Indian & $50(25.6)$ & $27(26.2)$ & $23(25.0)$ & \\
\hline Eurasian/others & $6(3.1)$ & $3(2.9)$ & $3(3.3)$ & \\
\hline Educational level & & & & 0.146 \\
\hline Non-tertiary & $74(37.9)$ & $44(42.7)$ & $30(32.6)$ & \\
\hline Tertiary \& above & $121(62.1)$ & $59(57.3)$ & $62(67.4)$ & \\
\hline Employment status & & & & 0.880 \\
\hline Non-employed & $52(26.7)$ & $27(26.2)$ & $25(27.2)$ & \\
\hline Employed & $143(73.3)$ & $76(73.8)$ & $67(72.8)$ & \\
\hline Monthly income status & & & & 0.658 \\
\hline $\operatorname{Low}(<\$ 3,000)$ & $105(53.8)$ & $57(55.3)$ & $48(52.2)$ & \\
\hline $\operatorname{High}(\geq \$ 3,000)$ & $90(46.2)$ & $46(44.7)$ & $44(47.8)$ & \\
\hline Housing type & & & & 0.206 \\
\hline Public & $158(81.0)$ & $80(77.7)$ & $78(84.8)$ & \\
\hline Private & $37(19.0)$ & $23(22.3)$ & $14(15.2)$ & \\
\hline Marital status & & & & 0.016 \\
\hline Single & $52(26.7)$ & $18(17.5)$ & $34(36.9)$ & \\
\hline Married & $136(69.7)$ & $80(77.6)$ & $56(60.9)$ & \\
\hline Widowed & $5(2.6)$ & $4(3.9)$ & $1(1.1)$ & \\
\hline Divorced & $2(1.0)$ & $1(1.0)$ & $1(1.1)$ & \\
\hline Smoking status & & & & 0.314 \\
\hline Non-smoker & $148(75.9)$ & $81(78.7)$ & $67(72.8)$ & \\
\hline Smoker & $17(8.7)$ & $6(5.8)$ & $11(12.0)$ & \\
\hline Former-smoker & $30(15.4)$ & $16(15.5)$ & 14 (15.2) & \\
\hline $\mathrm{CCl}$ & $0.26 \pm 0.69$ & $0.32 \pm 0.66$ & $0.18 \pm 0.71$ & 0.007 \\
\hline \multicolumn{5}{|l|}{ Clinical characteristics } \\
\hline Disease duration (yr) & $11.2 \pm 9.0$ & $12.6 \pm 9.6$ & $9.6 \pm 8.0$ & 0.018 \\
\hline Disease activity & & & & 0.012 \\
\hline Remission & $144(73.8)$ & $67(65.1)$ & $77(83.7)$ & \\
\hline Mild & $47(24.1)$ & $33(32.0)$ & $14(15.2)$ & \\
\hline Moderate & $4(2.1)$ & $3(2.9)$ & $1(1.1)$ & \\
\hline Severe & 0 & 0 & 0 & \\
\hline \multicolumn{5}{|l|}{ CD: disease location } \\
\hline |leitis & - & - & $29(31.5)$ & \\
\hline Ileocolitis & - & - & $39(42.4)$ & \\
\hline
\end{tabular}

(Continued to the next page) 
Table 1. Continued

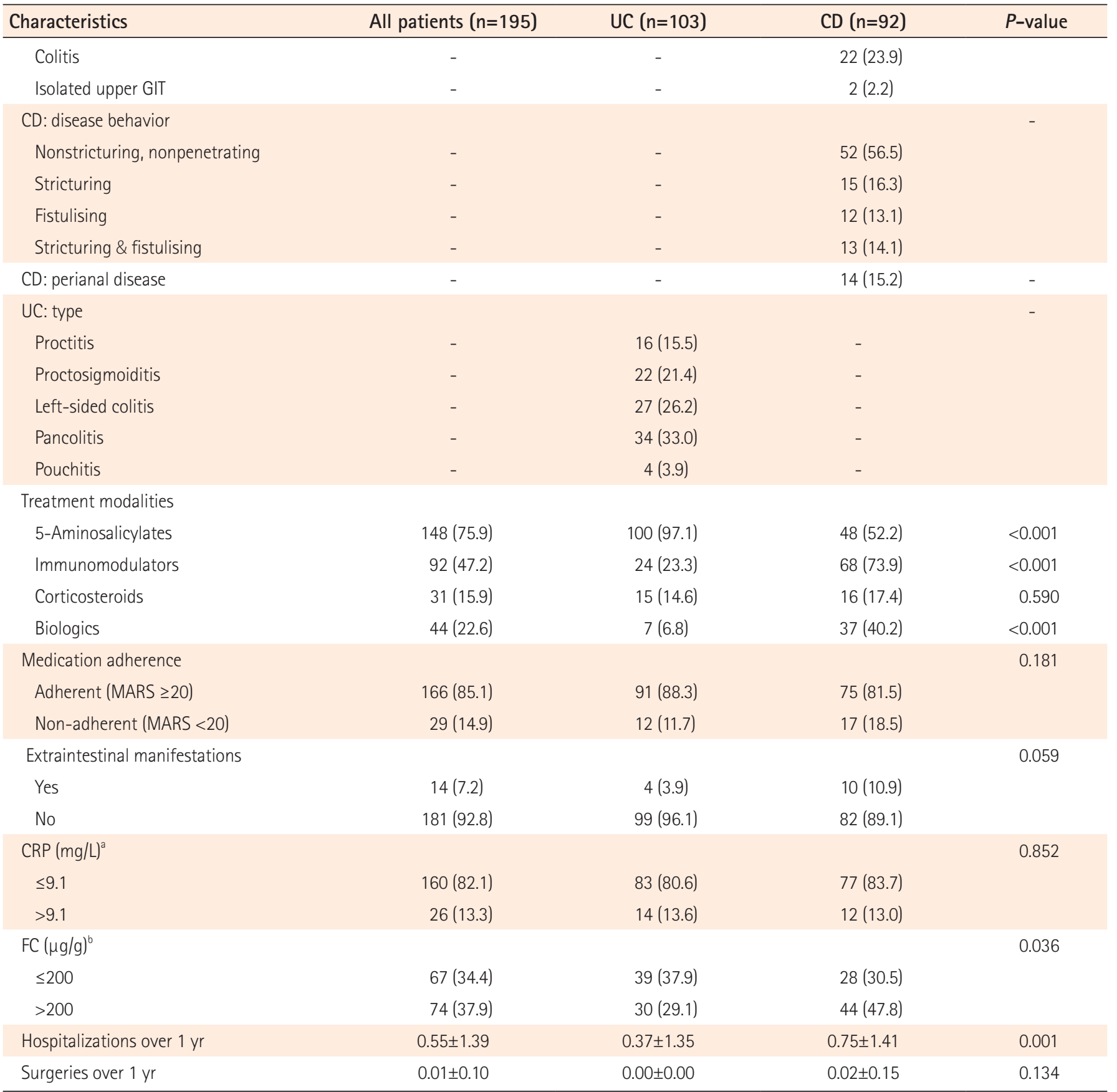

Values are presented as mean \pm SD or number (\%).

a9 Patients without CRP measured (6 UC, 3 CD).

${ }^{b} 54$ Patients without FC measured (34 UC, 20 CD).

CCI, Charlson Comorbidity Index; GIT, GI tract; MARS, Medication Adherence Report Scale; FC, fecal calprotectin.

are associated with the HRQoL of IBD patients. The respective HRQoL scores were used as dependent variables. The following demographic and clinical variables were included as covariates: age, gender (female/male), race (Chinese/non-Chinese), education (tertiary/non-tertiary), employment status (employed/non-employed), monthly income status (high $[\geq \$ 3,000]$ vs. low $[<\$ 3,000]$ ), housing (public/private), marital status (married/others), smoking status (smoker/former and non-smoker), Charlson Comorbidity Index, disease duration, disease severity (active/remission), use of 5-ASA, immuno- 
modulators, corticosteroids and biologics, medication adherence (high $[\mathrm{MARS} \geq 20$ ] vs. low $[\mathrm{MARS}<20]$ ), EIMs and number of IBD-related hospital admissions in the past year. These variables were selected based on literature reviews and clinical experience. ${ }^{7,13-17}$ A $P$-value of $<0.05$ was considered to be statistically significant.

\section{RESULTS}

\section{Demographics and Clinical Characteristics}

A total of 377 IBD patients were approached at the Singapore General Hospital IBD Centre for participation in the study. The final study population consisted of 195 patients (103 UC, 92 CD) (Fig. 1). The baseline demographics and clinical characteristics of patients included in the analyses are presented in Table 1. Patients with $\mathrm{CD}$ were significantly younger (mean $\pm \mathrm{SD}$, $42.3 \pm 15.8$ vs. $51.4 \pm 13.6, P<0.001)$, mostly not married $(60.9 \%$ vs. $77.7 \%, P=0.016)$ and with a lower CCI $(0.32 \pm 0.66$ vs. $0.18 \pm$ $0.71, P=0.007)$ than UC patients. No significant difference was observed when comparing other socio-demographic parameters between groups.

Patients diagnosed with UC had a longer disease duration than those diagnosed with $\mathrm{CD}$ ( $m e a n \pm \mathrm{SD}, 12.6 \pm 9.6$ vs. 9.6 \pm 8.0 , $P=0.018$ ). The majority of our participants were in disease remission (73.8\%), with a significantly greater percentage of CD patients in disease remission ( $83.7 \%$ vs. $65.1 \%, P=0.012$ ) compared with UC. The proportion of patients with FC $>200 \mu \mathrm{g} / \mathrm{g}$ was higher in the CD group ( $47.8 \%$ vs. $29.1 \%, P=0.036$ ) than in the UC group. The choices of treatment options for the 2 groups were also significantly different. Amino-salicylates were used in a greater majority of UC patients, as compared to CD patients ( $97 \%$ vs. $50 \%, P<0.001$ ). By contrast, the use of immunosuppressants and biologics were more common in the $\mathrm{CD}$ group than in the UC group ( $73.9 \%$ vs. $23.3 \%, P<0.001$ and $40.2 \%$ vs. $6.8 \%, P<0.001)$.

\section{HRQoL Scores in Patients with IBD}

The scores of the various HRQoL instruments are summarized

Table 2. Health-Related Quality of Life (HROoL) of Study Participants

\begin{tabular}{|c|c|c|c|c|c|}
\hline Measurements of $\mathrm{HRQoL}$ & $\begin{array}{l}\text { All patients } \\
(n=195)\end{array}$ & $\begin{array}{c}\text { UC } \\
(n=103)\end{array}$ & $\begin{array}{c}C D \\
(n=92)\end{array}$ & $\begin{array}{l}\text { Mean difference } \\
(C D-U C)\end{array}$ & $P$-value \\
\hline \multicolumn{6}{|l|}{ SIBDO scores } \\
\hline Bowel function & $17.4 \pm 3.3$ & $17.1 \pm 3.4$ & $17.7 \pm 3.2$ & 0.59 & 0.217 \\
\hline Emotional status & $16.4 \pm 3.7$ & $16.8 \pm 3.4$ & $15.9 \pm 4.0$ & -0.95 & 0.074 \\
\hline Systemic symptoms & $10.2 \pm 2.6$ & $10.3 \pm 2.5$ & $10.0 \pm 2.8$ & -0.36 & 0.339 \\
\hline Social performance & $12.0 \pm 2.5$ & $12.2 \pm 2.4$ & $11.8 \pm 2.7$ & -0.42 & 0.251 \\
\hline Total SIBDO score & $55.7 \pm 10.4$ & $56.5 \pm 9.4$ & $54.9 \pm 11.4$ & -1.59 & 0.287 \\
\hline \multicolumn{6}{|l|}{ SF-36 scores } \\
\hline Physical functioning & $86.4 \pm 17.6$ & $85.2 \pm 19.2$ & $87.8 \pm 15.7$ & 2.63 & 0.300 \\
\hline Role limitations (due to physical health problems) & $74.0 \pm 38.0$ & $75.5 \pm 36.7$ & $72.3 \pm 39.5$ & -3.20 & 0.558 \\
\hline Bodily pain & $79.4 \pm 23.0$ & $79.5 \pm 22.3$ & $79.3 \pm 23.7$ & -0.25 & 0.941 \\
\hline General health perceptions & $56.5 \pm 22.1$ & $59.9 \pm 22.0$ & $52.8 \pm 21.8$ & -7.13 & 0.024 \\
\hline Physical component summary & $74.1 \pm 19.2$ & $75.0 \pm 18.6$ & $73.0 \pm 20.0$ & -1.99 & 0.473 \\
\hline Social functioning & $83.2 \pm 21.2$ & $85.1 \pm 20.1$ & $81.1 \pm 22.2$ & -3.96 & 0.193 \\
\hline Role limitations (due to emotional problems) & $82.2 \pm 32.9$ & $84.8 \pm 29.8$ & $79.3 \pm 35.9$ & -5.44 & 0.254 \\
\hline Vitality or energy level & $57.0 \pm 20.3$ & $58.7 \pm 20.1$ & $55.1 \pm 20.5$ & -3.63 & 0.214 \\
\hline General mental health & $73.1 \pm 18.6$ & $74.6 \pm 16.4$ & $71.3 \pm 20.6$ & -3.34 & 0.217 \\
\hline Mental component summary & $73.4 \pm 19.0$ & $75.8 \pm 16.0$ & $70.6 \pm 21.6$ & -5.17 & 0.062 \\
\hline \multicolumn{6}{|l|}{$E 0-5 D-3 L$} \\
\hline Utility score & $0.8 \pm 0.2$ & $0.8 \pm 0.2$ & $0.8 \pm 0.2$ & -0.01 & 0.759 \\
\hline VAS & $71.2 \pm 16.5$ & $71.9 \pm 15.8$ & $70.4 \pm 17.3$ & -1.52 & 0.523 \\
\hline
\end{tabular}

Values are presented as mean \pm SD.

SIBDO, short IBD questionnaire; SF-36, Short Form-36 Health Survey; EQ-5D-3L, EuroQol 5-dimensions 3-levels; VAS, visual analogue scale. 
in Table 2. The mean \pm SD SIBDQ score was $55.7 \pm 10.4$ while the mean \pm SD SF-36 PCS and MCS were $74.1 \pm 19.2$ and $73.4 \pm$ 19.0 respectively. Patients had a mean \pm SD health utility of
$0.838 \pm 0.223$ based on EQ-5D-3L and a mean \pm SD VAS of $71.2 \pm$ 16.5. There were no significant differences in any of these HRQoL scores between UC and CD patients.

Table 3. Regression Coefficients of Variables Used in Multiple Linear Regression

\begin{tabular}{|c|c|c|c|c|c|}
\hline \multirow{2}{*}{ Independent variable (reference) } & \multicolumn{5}{|c|}{ Dependent variable } \\
\hline & SIBDQ & SF-36 PCS & SF-36 MCS & $E Q-5 D-3 L$ & VAS \\
\hline Age & 0.134 & 0.060 & $0.281^{\mathrm{a}}$ & -0.001 & $-0.272^{\mathrm{a}}$ \\
\hline \multicolumn{6}{|l|}{ Sex (male) } \\
\hline Female & -0.465 & -3.462 & -4.025 & -0.050 & -5.087 \\
\hline \multicolumn{6}{|l|}{ Race (non-Chinese) } \\
\hline Chinese & 0.092 & 0.731 & 1.464 & 0.017 & -1.951 \\
\hline \multicolumn{6}{|l|}{ Educational level (secondary/below) } \\
\hline Tertiary/above & 0.596 & 1.750 & 3.362 & 0.077 & 0.190 \\
\hline \multicolumn{6}{|c|}{ Employment status (unemployed/students/unable to work) } \\
\hline Employed & 3.831 & 5.552 & $9.738^{\mathrm{a}}$ & $0.104^{\mathrm{a}}$ & 1.275 \\
\hline \multicolumn{6}{|l|}{ Monthly income status $(<\$ 3,000)$} \\
\hline$\geq \$ 3,000$ & -0.855 & -1.747 & -1.217 & -0.031 & -0.716 \\
\hline \multicolumn{6}{|l|}{ Housing type (private residence) } \\
\hline Public residence & -3.230 & $-8.070^{\mathrm{a}}$ & -3.238 & -0.018 & $-9.207^{b}$ \\
\hline \multicolumn{6}{|l|}{ Marital status (single/widowed/divorced) } \\
\hline Married & 0.877 & -0.324 & 1.631 & 0.036 & 2.224 \\
\hline \multicolumn{6}{|l|}{ Smoking status (non-/former smoker) } \\
\hline Smoker & 2.777 & 6.809 & 1.513 & 0.099 & -0.522 \\
\hline Charlson Comorbidity Index & -0.491 & $-4.531^{\mathrm{a}}$ & -0.585 & 0.016 & 1.248 \\
\hline Disease duration & 0.060 & 0.105 & 0.160 & 0.002 & 0.160 \\
\hline \multicolumn{6}{|l|}{ Disease activity (remission) } \\
\hline Active disease & $-6.293^{c}$ & $-9.409^{b}$ & $-9.743^{b}$ & -0.051 & $-7.254^{\mathrm{a}}$ \\
\hline \multicolumn{6}{|l|}{ 5-Aminosalicylates (no) } \\
\hline Yes & -0.369 & -1.010 & -1.478 & -0.044 & -0.020 \\
\hline \multicolumn{6}{|l|}{ Immunomodulators (no) } \\
\hline Yes & -1.456 & -2.412 & -5.535 & -0.050 & -3.784 \\
\hline \multicolumn{6}{|l|}{ Corticosteroids (no) } \\
\hline Yes & $-7.392^{c}$ & $-10.390^{b}$ & $-8.827^{\mathrm{a}}$ & -0.053 & -2.428 \\
\hline \multicolumn{6}{|l|}{ Biologics (no) } \\
\hline Yes & 0.143 & -2.960 & -5.094 & -0.051 & -2.918 \\
\hline \multicolumn{6}{|l|}{ Medication adherence (low-MARS <20) } \\
\hline High-MARS $\geq 20$ & $4.049^{\mathrm{a}}$ & 4.470 & $1.320^{c}$ & 0.039 & $8.961^{b}$ \\
\hline \multicolumn{6}{|l|}{ Extraintestinal manifestation (absent) } \\
\hline Present & -3.456 & $-13.381^{\mathrm{a}}$ & 1.023 & -0.062 & 1.930 \\
\hline Hospitalizations over $1 \mathrm{yr}$ & 0.296 & 0.419 & 0.944 & 0.022 & 0.070 \\
\hline
\end{tabular}

Statistical significance: ${ }^{\mathrm{a}} \mathrm{P}<0.05,{ }^{\mathrm{b}} \mathrm{P}<0.01,{ }^{\mathrm{c}} P<0.001$.

SIBDQ, short IBD questionnaire; SF-36 PCS, physical component summary of Short Form-36; SF-36 MCS, mental component summary of Short Form36; EQ-5D-3L, Euro0ol 5-dimensions 3-levels; VAS, visual analogue scale of Euro0ol-5D; MARS, Medication Adherence Report Scale. 
Table 4. Health-Related Quality of Life (HROoL) of Study Participants Based on Disease Activity

\begin{tabular}{|c|c|c|c|c|c|}
\hline Measurements of HRQoL & $\begin{array}{l}\text { All patients } \\
\quad(n=195)\end{array}$ & $\begin{array}{l}\text { Remission } \\
(n=144)\end{array}$ & $\begin{array}{l}\text { Active } \\
(n=51)\end{array}$ & $\begin{array}{l}\text { Mean difference } \\
\text { (active-remission) }\end{array}$ & $P$-value \\
\hline \multicolumn{6}{|l|}{ SIBDO scores } \\
\hline Bowel function & $17.4 \pm 3.3$ & $18.0 \pm 2.9$ & $15.8 \pm 3.9$ & -2.15 & 0.001 \\
\hline Emotional status & $16.4 \pm 3.7$ & $16.7 \pm 3.6$ & $15.3 \pm 3.9$ & -1.44 & 0.016 \\
\hline Systemic symptoms & $10.2 \pm 2.6$ & $10.6 \pm 2.5$ & $9.0 \pm 2.7$ & -1.56 & $<0.001$ \\
\hline Social performance & $12.0 \pm 2.5$ & $12.4 \pm 2.3$ & $10.9 \pm 2.9$ & -1.55 & 0.001 \\
\hline Total SIBDO score & $55.7 \pm 10.4$ & $57.4 \pm 9.9$ & $51.0 \pm 10.4$ & -6.41 & $<0.001$ \\
\hline \multicolumn{6}{|l|}{ SF-36 scores } \\
\hline Physical functioning & $86.4 \pm 17.6$ & $86.4 \pm 18.5$ & $86.7 \pm 15.1$ & 0.31 & 0.914 \\
\hline Role limitations (due to physical health problems) & $74.0 \pm 38.0$ & $77.8 \pm 35.5$ & $63.2 \pm 42.8$ & -14.50 & 0.033 \\
\hline Bodily pain & $79.4 \pm 23.0$ & $81.9 \pm 21.1$ & $72.4 \pm 26.5$ & -9.57 & 0.023 \\
\hline General health perceptions & $56.5 \pm 22.1$ & $58.7 \pm 21.7$ & $50.5 \pm 22.3$ & -8.19 & 0.023 \\
\hline Physical component summary & $74.1 \pm 19.2$ & $76.2 \pm 18.5$ & $68.2 \pm 20.2$ & -8.00 & 0.010 \\
\hline Social functioning & $83.2 \pm 21.2$ & $85.9 \pm 20.2$ & $75.7 \pm 22.1$ & -10.11 & 0.003 \\
\hline Role limitations (due to emotional problems) & $82.2 \pm 32.9$ & $85.6 \pm 29.7$ & $72.5 \pm 39.3$ & -13.10 & 0.033 \\
\hline Vitality or energy level & $57.0 \pm 20.3$ & $59.6 \pm 19.4$ & $49.8 \pm 21.2$ & -9.78 & 0.003 \\
\hline General mental health & $73.1 \pm 18.6$ & $74.4 \pm 18.7$ & $69.4 \pm 17.7$ & -4.95 & 0.102 \\
\hline Mental component summary & $73.4 \pm 19.0$ & $75.7 \pm 18.7$ & $66.9 \pm 18.5$ & -8.80 & 0.004 \\
\hline \multicolumn{6}{|l|}{ EQ-5D-3L } \\
\hline Utility score & $0.8 \pm 0.2$ & $0.9 \pm 0.2$ & $0.8 \pm 0.2$ & -0.04 & 0.310 \\
\hline VAS & $71.2 \pm 16.5$ & $72.6 \pm 15.7$ & $67.1 \pm 18.0$ & -5.55 & 0.038 \\
\hline
\end{tabular}

Values are presented as mean $\pm \mathrm{SD}$.

SIBDO, short IBD questionnaire; SF-36, Short Form-36 Health Survey; EQ-5D-3L, EuroQol 5-dimensions 3-levels; VAS, visual analogue scale.

\section{Factors Associated with HRQoL}

In the multivariate analysis, presence of active disease $(b=-6.293$ [SIBDQ], -9.409 [PCS], -9.743 [MCS], -7.254 VAS]), use of corticosteroids $(\mathrm{b}=-7.392$ [SIBDQ], -10.390 [PCS], -8.827 [MCS]) and poor medication adherence $(b=-4.049$ [SIBDQ], -1.320 [MCS], -8.961 [VAS]) were significantly associated with lower HRQoL across all 3 instruments (Table 3). In particular, the HRQoL of the IBD patients based on their disease activity is shown in Table 4.

Presence of EIMs or comorbidities were associated with a significant decrease in patients' SF-36 PCS $(b=-13.381$ and -4.531 respectively). Employment ( $b=9.738$ [MCS], 0.104 [EQ5D-3L]) and public housing ( $\mathrm{b}=-8.070$ [PCS], -9.207 [VAS]) were socio-demographic factors that had significant influence on patients' generic HRQoL. Age ( $\mathrm{b}=0.281$ [MCS], -0.272 [VAS]) had a statistically significant impact on HRQoL but the magnitude was not clinically significant.

Other factors were associated with a clinically significant difference in patients' HRQoL. The use of immunomodulators or biologics resulted in a decrease in MCS ( $b=-5.535$ and -5.094 , respectively) with a magnitude greater than the MCID, while smokers had a better PCS ( $b=6.809)$ as compared to non-smokers or former smokers. However, these results were not statistically significant $(P>0.05)$.

\section{DISCUSSION}

The importance of assessing the HRQoL of patients with IBD is increasingly acknowledged in research and clinical care. It complements the conventional measures of disease activity, providing better insight into the overall impact of IBD on patients' lives and their unmet needs, thereby contribute to an improved patient care. ${ }^{35}$ While many studies examining the HRQoL of IBD patients and its associated factors have been conducted across various countries, this remains under-studied in Singapore. To the best of our knowledge, this is the first prospective study to measure the HRQoL of multi-ethnic Singaporean IBD patients. In this study, we used 3 different dis- 
ease-specific and generic HRQoL instruments (SIBDQ, SF-36 and EQ-5D-3L) to holistically assess patients' HRQoL.

The results of our study demonstrated that IBD patients had a reduced HRQoL. The mean SF-36 PCS and MCS as well as EQ-5D-3L scores of our study population were lower than the Singapore population norms. ${ }^{27,30}$ The difference in SF-36 scores from population norms ranged from 6.1 to 11.7 , and was substantially greater than the MCID for SF-36, especially in the dimensions of physical role limitations, general health and vitality (Supplementary Table 1). Likewise, the difference in mean EQ-5D utility scores from population norms $(-0.12)$ exceeded the defined MCID. These results are consistent with those of other studies across different countries. ${ }^{11,12}$ The mean total SIBDQ score obtained in our study was similar to that of studies conducted in the United States and in Europe, which also reflected impairment in IBD patients' HRQoL. ${ }^{36,37}$ Therefore, it is imperative to assess their HRQoL and address the underlying causes of this impairment.

We found no significant differences between the HRQoL of UC and CD patients in this study. This indicates that disease type is not a key determinant of HRQoL in IBD patients. This result is consistent with various other studies. ${ }^{7,13,15,38}$ Although some review articles have found that patients with CD have poorer HRQoL than those with $\mathrm{UC}^{39,40}$ this was not evident in our study. In those studies, the difference in HRQoL was partly attributed to CD patients having a comparatively more severe disease course as well as higher incidence of surgical procedures. We postulated that as the majority of our patients were in disease remission, we were unable to pick up differences in HRQoL scores between the 2 groups.

Amongst the factors found to be associated with poorer HRQoL, disease activity has frequently been reported as a significant predictor of IBD patients' HRQoL, regardless of the instruments used. ${ }^{7-9,11-16}$ In our study, a strong inverse relationship existed between disease activity and HRQoL across 3 instruments. This indicates that active disease affects multiple aspects of HRQoL. High disease activity often lead to disabling symptoms, including abdominal pain, diarrhea and fatigue. These symptoms worsen during relapse, affecting patients' daily activities and personal productivity. ${ }^{9,38,41}$ Since disease activity has such an extensive effect on HRQoL, the use of effective treatment regimens that can effectively maintain disease remission and normalize HRQoL through resolution of symptoms are of great importance. ${ }^{42}$

Our analysis has also shown that corticosteroids use independently resulted in a marked decrease in HRQoL. This has also been previously reported. ${ }^{16,20,36,41}$ Corticosteroids are often given to IBD patients with an acute disease flare, characterized by a worsening of symptoms. Hence, the use of corticosteroids is a clinical factor related to disease activity, resulting in a similar decrease in HRQoL. However, additional analyses were performed to test the interaction between disease activity and corticosteroids, which was found to be not statistically significant. Therefore, the negative side-effect profiles of steroid therapy could be a more likely reason for its independent association with HRQoL, given that it adds to patients' diseaserelated worries and concerns, leading to a poorer perception of their health status. ${ }^{8}$

In this study, patients with poor medication adherence had lower HRQoL scores. Although this association between adherence and HRQoL is not well-studied, similar findings were observed in other adult and pediatric IBD populations but not in a Hungarian IBD population. ${ }^{43-45}$ Despite the conflicting results, the impact of poor medication adherence is increased frequency of relapses, higher rate of complications and increased healthcare cost. ${ }^{46-48}$ Conversely, medication adherence would reduce these risks and lead to better HRQoL. Moreover, patients who are adherent are often more proactive in taking care of their health and hence more likely to achieve better disease control. In light of this finding, further research should be conducted to better understand and address the causes of medication non-adherence in IBD patients.

Presence of EIMs and comorbidities both independently caused a significant reduction in patients' SF-36 PCS scores. These associations were similarly reported in other IBD studies which demonstrated that IBD patients with EIMs and coexisting chronic conditions face greater disablement in their daily living due to greater symptom burden, high pill burden and a decreased sense of well-being. ${ }^{42,49,50}$

The socio-demographic factors that were identified as independent predictors of HRQoL include employment status and housing type. Our study participants who were in full- or parttime employment and those residing in private housing had significantly higher generic HRQoL scores. This could be because patients who are working might have better financial support while patients living in private housing could be of higher socio-economic status. Hence, this group of patients could face less financial concerns. ${ }^{50}$ Likewise, many studies have shown that patients who are not working or are unable to work have poorer HRQoL. ${ }^{5,13,14,43}$ Since IBD patients face considerable treatment and healthcare costs, it is important to consider patient's need for financial and social support servic- 
es, especially for those with work disabilities or lower socioeconomic status.

The association between age and HRQoL of IBD patients remains controversial. In certain populations, older patients had lower HRQoL scores while other studies found no significant association. ${ }^{11,13,15,16,38}$ In our study, the associations between age and SF-36 MCS or EQ-5D VAS were statistically significant but not clinically significant. Similar to the results of a US study, younger patients had lower MCS but higher VAS when compared to older patients. ${ }^{36}$ It is likely that younger patients are less able to cope with the chronicity of IBD, disease flares and complications, especially if they are at the prime of their adulthood. On the other hand, the lower perceived health state of older patients could be due to age-related decline, comorbidity burden, unemployment and reduction in functional independence. ${ }^{51,52}$ To address these issues, IBD patients are encouraged to join the local IBD patient support group, in which they can relate their experiences and share advice and coping strategies. This would give them additional moral support and increased self-confidence which is needful in their journey living with IBD. ${ }^{53}$

While our results could be useful in future efforts to improve the quality of care for patients with IBD, it is important to recognize the limitations of this study. First, laboratory tests were ordered at the discretion of the physician. As a result, there were a considerable number of patients without CRP and FC readings. Hence, we were unable to include these objective measures as explanatory variables in the analysis. Instead, we circumvented this problem through the use of established disease activity indices. Second, a majority of the patients recruited had mild disease or were in clinical remission; none of our participants had severe disease activity and a small number of patients presented with moderate disease. As such, our results might not accurately reflect the HRQoL of patients with more severe disease states. Third, as this is a cross-sectional study, our results could only reflect the association between selected factors and HRQoL but could not draw causal inferences. Nonetheless, this study adds to the current literature, providing insight into the HRQoL of patients with IBD in Singapore.

In conclusion, our study has shown that HRQoL is impaired among Singaporean patients with IBD and that the magnitude of this impairment is similar in both UC and CD patients. Clinical characteristics are better determinants of their HRQoL than socio-demographic factors. In particular, more attention should be given to IBD patients with active disease, corticosteroid use and poor medication adherence as these factors re- sulted in a significant reduction in HRQoL across all 3 instruments. Greater awareness of the impact of IBD on patients' HRQoL would improve the holistic management of IBD patients.

\section{FINANCIAL SUPPORT}

The authors received no financial support for the research, authorship, and/or publication of this article.

\section{CONFLICT OF INTEREST}

No potential conflict of interest relevant to this article was reported.

\section{AUTHOR CONTRIBUTION}

Conceptualization: Ong WC and Cheen HH. Methodology: Ong WC, Chenn HH, Wee HL, and Lim TG. Formal analysis: Ho YM, Hu W, Lee YY, Gao C, Tan YZ, Cheen HH, and Ong WC. Funding acquisition: Nil. Project administration: Wee HL and Lim TG. Visualization: Ho YM, Hu W, Lee YY, Gao C, Tan YZ, Cheen HH, and Ong WC. Writing-original draft: Ho YM, Hu W, Lee YY, Gao C, Tan YZ, Cheen HH, and Ong WC.

\section{ACKNOWLEDGEMENTS}

We are grateful to the IBD physicians (Dr. Brian John Schwender Dr. Webber Chan Pak Wo, Dr. Chris Kong San Choon, Dr. Chuah Sai Wei and Dr. Shim Hang Hock) for their important contribution to this study.

\section{REFERENCES}

1. Elson CO, Cong Y. Host-microbiota interactions in inflammatory bowel disease. Gut Microbes 2012;3:332-344.

2. Ng SC, Tang W, Ching JY, et al. Incidence and phenotype of inflammatory bowel disease based on results from the Asiapacific Crohn's and colitis epidemiology study. Gastroenterology 2013;145:158-165.

3. Gan E. Bowel disease sufferers at higher risk of anxiety. TODAY Web site. https://www.todayonline.com/daily-focus/ bowel-disease-sufferers-higher-risk-anxiety. Accessed August $10,2016$.

4. Colì R, Corrado A, Cantatore FP. Rheumatologic and extraintestinal manifestations of inflammatory bowel diseases. Ann 
Med 2016;48:577-585.

5. Bernklev T, Jahnsen J, Henriksen M, et al. Relationship between sick leave, unemployment, disability, and health-related quality of life in patients with inflammatory bowel disease. Inflamm Bowel Dis 2006;12:402-412.

6. Keeton RL, Mikocka-Walus A, Andrews JM. Concerns and worries in people living with inflammatory bowel disease (IBD): a mixed methods study. J Psychosom Res 2015;78:573578.

7. Casellas F, López-Vivancos J, Casado A, Malagelada JR. Factors affecting health related quality of life of patients with inflammatory bowel disease. Qual Life Res 2002;11:775-781.

8. Drossman DA, Patrick DL, Mitchell CM, Zagami EA, Appelbaum MI. Health-related quality of life in inflammatory bowel disease. Functional status and patient worries and concerns. Dig Dis Sci 1989;34:1379-1386.

9. Larsson K, Lööf L, Rönnblom A, Nordin K. Quality of life for patients with exacerbation in inflammatory bowel disease and how they cope with disease activity. J Psychosom Res 2008;64:139-148.

10. Porter ME. What is value in health care? N Engl J Med 2010; 363:2477-2481.

11. Bernklev T, Jahnsen J, Lygren I, Henriksen M, Vatn M, Moum B. Health-related quality of life in patients with inflammatory bowel disease measured with the short form-36: psychometric assessments and a comparison with general population norms. Inflamm Bowel Dis 2005;11:909-918.

12. Love JR, Irvine EJ, Fedorak RN. Quality of life in inflammatory bowel disease. J Clin Gastroenterol 1992;14:15-19.

13. Zhou Y, Ren W, Irvine EJ, Yang D. Assessing health-related quality of life in patients with inflammatory bowel disease in Zhejiang, China. J Clin Nurs 2010;19:79-88.

14. Nurmi E, Haapamäki J, Paavilainen E, Rantanen A, Hillilä M, Arkkila P. The burden of inflammatory bowel disease on health care utilization and quality of life. Scand J Gastroenterol 2013; 48:51-57.

15. Pallis AG, Vlachonikolis IG, Mouzas IA. Assessing health-related quality of life in patients with inflammatory bowel disease, in Crete, Greece. BMC Gastroenterol 2002;2:1.

16. Haapamäki J, Turunen U, Roine RP, Färkkilä MA, Arkkila PE. Impact of demographic factors, medication and symptoms on disease-specific quality of life in inflammatory bowel disease. Qual Life Res 2009;18:961-969.

17. Casellas F, Arenas JI, Baudet JS, et al. Impairment of health-related quality of life in patients with inflammatory bowel disease: a Spanish multicenter study. Inflamm Bowel Dis 2005;
11:488-496.

18. Levenstein S, Li Z, Almer S, et al. Cross-cultural variation in disease-related concerns among patients with inflammatory bowel disease. Am J Gastroenterol 2001;96:1822-1830.

19. Petrak F, Hardt J, Clement T, Börner N, Egle UT, Hoffmann SO. Impaired health-related quality of life in inflammatory bowel diseases: psychosocial impact and coping styles in a national German sample. Scand J Gastroenterol 2001;36:375-382.

20. Zheng K, Zhang S, Wang C, Zhao W, Shen H. Health-related quality of life in Chinese patients with mild and moderately active ulcerative colitis. PLoS One 2015;10:e0124211.

21. Charlson ME, Pompei P, Ales KL, MacKenzie CR. A new method of classifying prognostic comorbidity in longitudinal studies: development and validation. J Chronic Dis 1987;40:373383.

22. Ediger JP, Walker JR, Graff L, et al. Predictors of medication adherence in inflammatory bowel disease. Am J Gastroenterol 2007;102:1417-1426.

23. Irvine EJ, Zhou Q, Thompson AK. The Short Inflammatory Bowel Disease Questionnaire: a quality of life instrument for community physicians managing inflammatory bowel disease. CCRPT Investigators. Canadian Crohn's Relapse Prevention Trial. Am J Gastroenterol 1996;91:1571-1578.

24. Alrubaiy L, Rikaby I, Dodds P, Hutchings HA, Williams JG. Systematic review of health-related quality of life measures for inflammatory bowel disease. J Crohns Colitis 2015;9:284-292.

25. Ware JE Jr, Sherbourne CD. The MOS 36-item short-form health survey (SF-36). I. Conceptual framework and item selection. Med Care 1992;30:473-483.

26. Coteur G, Feagan B, Keininger DL, Kosinski M. Evaluation of the meaningfulness of health-related quality of life improvements as assessed by the SF-36 and the EQ-5D VAS in patients with active Crohn's disease. Aliment Pharmacol Ther 2009;29: 1032-1041.

27. Thumboo J, Chan SP, Machin D, et al. Measuring health-related quality of life in Singapore: normal values for the English and Chinese SF-36 Health Survey. Ann Acad Med Singapore 2002;31:366-374.

28. Luo N, Fones CS, Thumboo J, Li SC. Factors influencing healthrelated quality of life of Asians with anxiety disorders in Singapore. Qual Life Res 2004;13:557-565.

29. Stark RG, Reitmeir P, Leidl R, König HH. Validity, reliability, and responsiveness of the EQ-5D in inflammatory bowel disease in Germany. Inflamm Bowel Dis 2010;16:42-51.

30. Abdin E, Subramaniam M, Vaingankar JA, Luo N, Chong SA. Measuring health-related quality of life among adults in Sin- 
gapore: population norms for the EQ-5D. Qual Life Res 2013; 22:2983-2991.

31. Luo N, Chew LH, Fong KY, et al. Validity and reliability of the EQ-5D self-report questionnaire in English-speaking Asian patients with rheumatic diseases in Singapore. Qual Life Res 2003;12:87-92.

32. EuroQol Group. EuroQol: a new facility for the measurement of health-related quality of life. Health Policy 1990;16:199-208.

33. Lewis JD, Chuai S, Nessel L, Lichtenstein GR, Aberra FN, Ellenberg JH. Use of the noninvasive components of the Mayo score to assess clinical response in ulcerative colitis. Inflamm Bowel Dis 2008;14:1660-1666.

34. Harvey RF, Bradshaw JM. A simple index of Crohn's-disease activity. Lancet 1980;1:514.

35. Tabibian A, Tabibian JH, Beckman LJ, Raffals LL, Papadakis KA, Kane SV. Predictors of health-related quality of life and adherence in Crohn's disease and ulcerative colitis: implications for clinical management. Dig Dis Sci 2015;60:1366-1374.

36. Velonias G, Conway G, Andrews E, et al. Older age- and healthrelated quality of life in inflammatory bowel diseases. Inflamm Bowel Dis 2017;23:283-288.

37. Burisch J, Weimers P, Pedersen N, et al. Health-related quality of life improves during one year of medical and surgical treatment in a European population-based inception cohort of patients with inflammatory bowel disease: an ECCO-EpiCom study. J Crohns Colitis 2014;8:1030-1042.

38. Graff LA, Walker JR, Lix L, et al. The relationship of inflammatory bowel disease type and activity to psychological functioning and quality of life. Clin Gastroenterol Hepatol 2006;4:14911501.

39. Cohen RD. The quality of life in patients with Crohn's disease. Aliment Pharmacol Ther 2002;16:1603-1609.

40. Sainsbury A, Heatley RV. Review article: psychosocial factors in the quality of life of patients with inflammatory bowel disease. Aliment Pharmacol Ther 2005;21:499-508.

41. Romberg-Camps MJ, Bol Y, Dagnelie PC, et al. Fatigue and health-related quality of life in inflammatory bowel disease: results from a population-based study in the Netherlands: the IBD-South Limburg cohort. Inflamm Bowel Dis 2010;16:21372147.

42. Han SW, McColl E, Barton JR, James P, Steen IN, Welfare MR.
Predictors of quality of life in ulcerative colitis: the importance of symptoms and illness representations. Inflamm Bowel Dis 2005;11:24-34.

43. Varni JW, Shulman RJ, Self MM, et al. Perceived medication adherence barriers mediating effects between gastrointestinal symptoms and health-related quality of life in pediatric inflammatory bowel disease. Qual Life Res 2018;27:195-204.

44. Hommel KA, Davis CM, Baldassano RN. Medication adherence and quality of life in pediatric inflammatory bowel disease. J Pediatr Psychol 2008;33:867-874.

45. Horváth G, Farkas K, Hollósi R, et al. Is there any association between impaired health-related quality of life and non-adherence to medical therapy in inflammatory bowel disease? Scand J Gastroenterol 2012;47:1298-1303.

46. Kane S, Huo D, Aikens J, Hanauer S. Medication nonadherence and the outcomes of patients with quiescent ulcerative colitis. Am J Med 2003;114:39-43.

47. van der Have M, Oldenburg B, Kaptein AA, et al. Non-adherence to Anti-TNF therapy is associated with illness perceptions and clinical outcomes in outpatients with inflammatory bowel disease: results from a prospective multicentre study. J Crohns Colitis 2016;10:549-555.

48. Kane S, Shaya F. Medication non-adherence is associated with increased medical health care costs. Dig Dis Sci 2008;53:10201024.

49. Haapamäki J, Roine RP, Turunen U, Färkkilä MA, Arkkila PE. Increased risk for coronary heart disease, asthma, and connective tissue diseases in inflammatory bowel disease. J Crohns Colitis 2011;5:41-47.

50. Hjortswang H, Ström M, Almer S. Health-related quality of life in Swedish patients with ulcerative colitis. Am J Gastroenterol 1998;93:2203-2211.

51. Netuveli G, Blane D. Quality of life in older ages. Br Med Bull 2008;85:113-126.

52. Webb E, Blane D, McMunn A, Netuveli G. Proximal predictors of change in quality of life at older ages. J Epidemiol Community Health 2011;65:542-547.

53. Swarup N, Nayak S, Lee J, et al. Forming a support group for people affected by inflammatory bowel disease. Patient Prefer Adherence 2017;11:277-281. 
See "Health-related quality of life of patients with inflammatory bowel disease in Singapore" on page $107-118$.

Supplementary Table 1. SF-36 Scores of Study Population and Singapore's General Population

\begin{tabular}{|c|c|c|c|c|c|}
\hline & \multicolumn{2}{|c|}{$\begin{array}{l}\text { IBD patients } \\
\quad(n=195)\end{array}$} & \multicolumn{2}{|c|}{$\begin{array}{l}\text { Singapore population norms }{ }^{a} \\
\qquad(n=5,503)\end{array}$} & \multirow{2}{*}{$\begin{array}{c}\text { Mean } \\
\text { difference }\end{array}$} \\
\hline & Mean & SD & Mean & SD & \\
\hline Role limitations & 74.0 & 38.0 & 84.7 & 34.4 & -10.7 \\
\hline Bodily pain & 79.4 & 23.0 & 80.9 & 21.9 & -1.5 \\
\hline PCS & 74.1 & & 79.3 & & \\
\hline Vitality or energy level & 57.0 & 20.3 & 63.1 & 16.9 & -6.1 \\
\hline Social functioning & 83.2 & 21.2 & 83.5 & 20.8 & -0.3 \\
\hline Role limitations & 82.2 & 32.9 & 81.9 & 35.2 & 0.3 \\
\hline
\end{tabular}

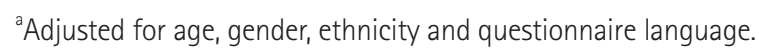

PCS, physical component summary; MCS, mental component summary. 